\title{
Comparison of Beinaglutide Versus Metformin for Weight Loss in Overweight and Obese Non-diabetic Patients
}

\section{(๑) $\odot \Theta$}

\author{
Authors \\ Lijun Gao*, Hong Huang*, Lu Zhang*, Ningjing Zhang, Yuzhe Fu, Dalong Zhu, Yan Bi ${ }^{\mathbb{D}}$, Wenhuan Feng ${ }^{\mathbb{D}}$
}

\begin{abstract}
Affiliation
Department of Endocrinology, Drum Tower Hospital Affiliated to Nanjing University Medical School, Nanjing, China
\end{abstract}

Key words

Glucagon-like peptide-1 receptor agonist, Biguanides,

Weight loss ratio, Body composition

$\begin{array}{ll}\text { received } & 02.03 .2021 \\ \text { revised } & 27.07 .2021 \\ \text { accepted } & 10.08 .2021\end{array}$

published online $\quad 02.12 .2021$

\section{Bibliography}

Exp Clin Endocrinol Diabetes 2022; 130: 358-367

DOI 10.1055/a-1608-0345

ISSN $0947-7349$

(c) 2021. The Author(s).

This is an open access article published by Thieme under the terms of the Creative Commons Attribution-NonDerivative-NonCommercial-License, permitting copying and reproduction so long as the original work is given appropriate credit. Contents may not be used for commercial purposes, or adapted, remixed, transformed or built upon. (https://creativecommons. org/licenses/by-nc-nd/4.0/)

Georg Thieme Verlag, Rüdigerstraße 14

70469 Stuttgart, Germany

\section{Correspondence}

Wen-Huan Feng, M.D.

Department of Endocrinology

Drum Tower Hospital Affiliated to Nanjing University Medical School

Nanjing

Zhongshan Road 321

210008 Nanjing

China

Tel: + 86-025-83106666-61430, Fax: 86-25-83105313

fengwh501@163.com
Yan Bi, M.D., Ph.D.

Department of Endocrinology

Drum Tower Hospital Affiliated to Nanjing University Medical

School

Nanjing

Zhongshan Road 321

210008 Nanjing

China

Tel.: + 86-025-83106666-61430, Fax: 86-25-83105313

biyan@nju.edu.cn

Supplementary Material is available under

https://doi.org/10.1055/a-1608-0345

\section{ABSTRACT}

Purpose We compared the efficacy and safety of beinaglutide, a glucagon-like peptide-1 (GLP-1) analogue with metformin in lowering the bodyweight of patients who were overweight/obese and non-diabetic.

Patients and Methods Seventy-eight non-diabetic patients were randomly selected and beinaglutide or metformin was administered for 12 weeks. The primary endpoints were changes in body weight and the proportions of patients who lost $\geq 5$ and $\geq 10 \%$ of their baseline body weights.

Results A total of 64 patients completed the study; patients in the beinaglutide group exhibited more bodyweight loss than those in the metformin group [ $(9.5 \pm 0.8 \% ; 9.1 \pm 0.9 \mathrm{~kg})$ and $(5.1 \pm 0.9 \% ; 4.5 \pm 0.8 \mathrm{~kg})$, respectively, corresponding to a difference of approximately $4.5 \mathrm{~kg}$ (95\% confidence interval, $2.2-6.9 \mathrm{~kg} ; P<0.01)]$. In the beinaglutide group, 90.6 and $40.6 \%$ of the patients lost $\geq 5$ and $\geq 10 \%$ of their body weight, respectively, whereas, in the metformin group, these rates were 46.9 and $12.5 \%$, respectively $(P<0.01$ and $P<0.05)$. Weight loss following beinaglutide treatment mainly resulted from the loss of fat mass. Compared to metformin, beinaglutide induced a greater decrease in the body mass index, weight circumference, percent body fat, and body fat mass (total, trunk, limb, android, and gynoid). Additionally, beinaglutide decreased serum insulin levels and ameliorated insulin resistance.

Conclusions Beinaglutide is more efficient than metformin at reducing weight and fat mass in patients who are overweight/ obese and non-diabetic. Beinaglutide may be a useful therapeutic option for overweight/obesity control in the Chinese population.

"These authors equally contributed to this work. 


\section{Introduction}

Obesity is currently a major public health issue worldwide. A weight loss of 5-10\% has been proven to prevent and alleviate obesity-related complications [1-4]. Obesity management depends mainly on lifestyle interventions, medications, and bariatric surgery according to recommendations based on the patient's body mass index (BMI) [5]. Although lifestyle intervention is considered the cornerstone for the treatment of overweight and obese individuals, it is difficult to maintain weight loss using this approach alone [6]. In China, orlistat is the only drug approved for treating obese patients who do not have type 2 diabetes mellitus (T2DM). In Western countries, liraglutide, a glucagon-like peptide- 1 receptor agonist (GLP-1RA), is used for weight loss in non-diabetic obese patients [5, 7]. GLP-1RAs have been shown to reduce body weight in patients with T2DM and/or obese/overweight patients by suppressing appetite and delaying gastric emptying. These effects likely occur through the combined effect of the drug on the hypothalamus and the gastrointestinal tract [8-11].

The GLP-1RAs approved for the treatment of T2D in China, including beinaglutide and exenatide (short-acting GLP-1RAs), liraglutide and lixisenatide (daily-acting GLP-1RAs), and dulaglutide and loxenatide (weekly-acting GLP-1RAs) have different durations of action [12]. Different from other GLP-1RAs, beinaglutide is a recombinant GLP-1 that has $100 \%$ homology to human GLP-1, and so can simulate the physiological mode of action of GLP-1, reduce food intake by suppressing appetite and delaying gastric emptying when injected before each meal [13]. The initial dose of beinaglutide used for the treatment of T2DM is $0.1 \mathrm{mg}(50 \mu \mathrm{L})$, three times a day and after two weeks of treatment, the dose is increased to $0.2 \mathrm{mg}(100 \mu \mathrm{L})$, three times a day [14]. According to one retrospective study, there is a mean reduction in body weight of $10.05 \mathrm{~kg}$ after three months of treatment with beinaglutide in patients with T2DM [15]. Metformin, a biguanide oral hypoglycaemic agent, which has been shown to exhibit favourable weight loss effects in patients with T2DM [16-18], is widely used in patients who are overweight/obese and insulin-resistant, although it has not been approved for the treatment of obesity in the absence of T2DM $[19,20]$. It is unclear whether beinaglutide is beneficial for weight loss in patients who are overweight/obese but not diabetic and if the weight loss is different compared to that induced by metformin. Here, we assessed the effects and safety of beinaglutide in comparison with those of metformin at reducing the body weights of overweight/obese non-diabetic individuals.

\section{Materials and Methods}

\section{Study design}

This 12-week randomised, open, controlled, and a single-site clinical trial was conducted from May 2018 to December 2019 in the Department of Endocrinology, Drum Tower Hospital Affiliated with Nanjing University Medical School (ClinicalTrials.gov, number NCT03593668). Written informed consent was obtained from each participant prior to enrolment in the study. The trial received ethical approval from the Ethics Committee of Nanjing Drum Tower Hospital and was performed according to the Declaration of Helsinki.
Enrolled participants met the guidelines for the diagnosis and treatment of obesity in China, namely a BMI of $28-37.5 \mathrm{~kg} / \mathrm{m}^{2}$ or at least $24 \mathrm{~kg} / \mathrm{m}^{2}$ accompanied by at least one obesity-related complication, such as dyslipidaemia, impaired glucose tolerance, impaired fasting glucose, non-alcoholic fatty liver (NAFLD), and hyperuricaemia [21]. Other inclusion criteria were age between 18-70 years and had achieved $a<5 \%$ weight change after lifestyle intervention in the previous three months. Exclusion criteria included 1) not having diabetes mellitus, 2) use of weight-lowering medications or participation in other clinical studies three months prior to screening, 3) obesity induced by drug therapy, such as administration of systemic corticosteroids, 4) liver dysfunction [total bilirubin $>34.2 \mu \mathrm{mol} / \mathrm{L}$ or alanine transaminase (ALT) or aspartate transaminase (AST) levels more than three times the upper limit of the normal value], 5) renal dysfunction (serum creatinine $\geq 133$ and $\geq 124 \mu \mathrm{mol} / \mathrm{L}$ for male and female patients, respectively), 6) known or suspected alcohol or narcotics abuse within the previous 6 months, 7) history of severe psychiatric disorders, 8 ) personal or family history of medullary thyroid carcinoma or multiple endocrine neoplasia type 2 , or 9) breastfeeding mothers, pregnant women, or women unwilling to use appropriate contraception methods.

\section{Study treatment}

After a one-week screening period, a region random number table generated by Stata software was used to randomly assign the 78 participants (1:1) to receive $0.2 \mathrm{mg}$ beinaglutide (Shanghai Benemae Pharmaceutical Corporation, Shanghai, China) subcutaneously or $0.5 \mathrm{~g}$ metformin orally, three times per day for 12 weeks ( $\triangleright$ Fig. 1). Beinaglutide was initiated at $0.1 \mathrm{mg}$ before dinner, $0.1 \mathrm{mg}$ before breakfast and dinner two days later, and then $0.1 \mathrm{mg}$ before three meals two days later. The dose was then increased by $0.1 \mathrm{mg}$ every two days until the final dose was reached $(0.2 \mathrm{mg}$ before three meals). The starting dose of metformin was $0.25 \mathrm{~g}$ before dinner, which was increased to $0.5 \mathrm{~g}$ three times daily in the same manner as for beinaglutide. The dose escalation schedules are mentioned in Supplemental Table 1.

Patients were evaluated at baseline and every four weeks. Bodyweight, waist circumference, BMI, vital signs, and adverse events were assessed at each visit. Baseline examination was performed in patients before the run-in phase. Body composition was evaluated by dual-energy X-ray (DXA) (Lunar iDXA, Encore 13.4; GE Healthcare, Little Chalfont, UK) and bioelectrical impedance analysis (BIA) (InBody770; InBody Co., Ltd. Cheonan-si, Chungcheongnan-do, Korea). Basal metabolic rate was measured by BIA. Controlled attenuation parameter (CAP) and liver stiffness measurement (LSM) were assessed by transient elastography technology (FibroTouch, FT70000; Heskell Medical Technology Co., Ltd, Wuxi, Jiangsu, China). Finally, laboratory parameters, including glycated haemoglobin A1c, serum glucose, insulin levels at 0,30 , and 120 min during a 75 -g glucose tolerance test, hepatic and renal function, and lipid profiles were monitored at baseline and the end of the study. The calculated values of fasting insulin $\times$ fasting blood glucose/22.5 were defined as insulin resistance (HOMA-IR).

Both groups were counselled on lifestyle modification. All participants were advised to consume a limited-energy balanced diet (women, 1000-1200 kcal per day; men, 1500-1800 kcal per day) and to engage in at least 150 min of physical activity per week throughout the trial. 


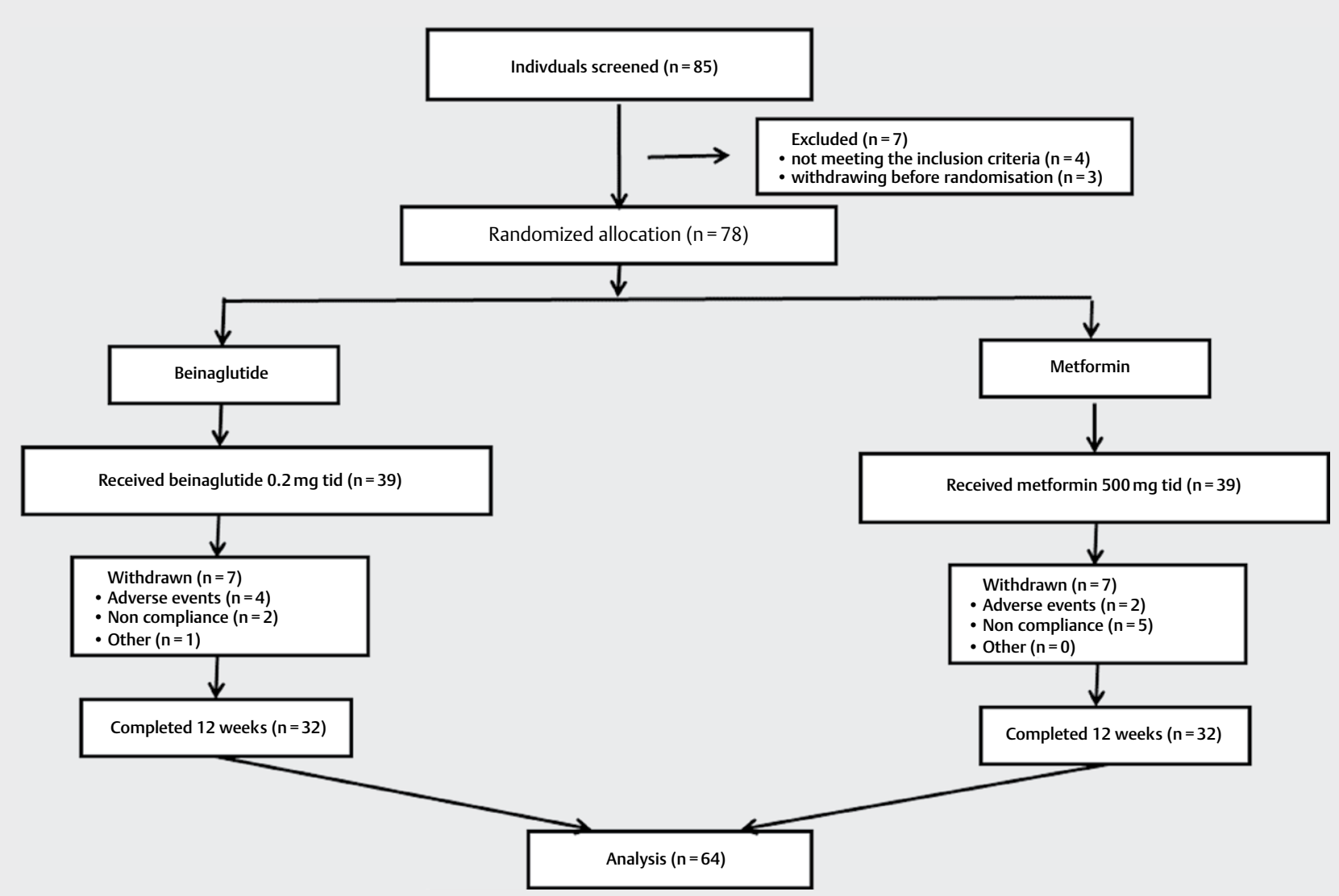

- Fig. 1 A flow chart of the enrolment of the study subjects.

\section{Outcomes}

The primary endpoints were a change in body weight from baseline and the proportion of people who lost $\geq 5$ or $\geq 10 \%$ of their initial weight. Secondary endpoints included changes in BMI, waist circumference, blood pressure, body composition, glucose and lipid metabolism, HOMA-IR, and serum uric acid as well as improvement of fatty liver and adverse events.

Adverse events during the trial period, with onset on or after the initiation of treatment and within 14 days after the end of the treatment, were reported. Serious adverse events were immediately reported to the Research Ethics Board of the Research Hospital and the Institutional Review Board of the Drug Clinical Trial Agency Office.

\section{Statistical analysis}

We predicted that beinaglutide would be superior to metformin in reducing body weight. Based on previous studies [10, 22], GLP1 RAs and metformin decreased body weight by around 3.4 \pm 3.0 and $1.9 \pm 2.9 \mathrm{~kg}$, respectively. We conservatively estimated that beinaglutide would decrease body weight from baseline by $4 \mathrm{~kg}$. Fifty participants ( 25 per arm) provided $>80 \%$ power between arms with an alpha of 0.05 . Considering a drop-out rate of $20 \%$, a total of 78 patients were recruited.

SPSS version 22.0 software (SPSS Inc., Chicago, IL, USA) was used for statistical analyses. For continuous variables, a paired Stu- dent's t-test or Wilcoxon matched-pairs signed-rank test was used for comparisons within groups. The differences between the treatment groups after adjusting for baseline values were compared by an independent sample $t$-test. The chi-squared test was used to evaluate the differences in categorical variables between groups. The data are expressed as means \pm standard deviations (SD). $P<0.05$ was defined as statistical significance.

\section{Results}

\section{Clinical characteristics of the study participants}

A total of 85 participants were screened, and 78 were randomly assigned to the two treatment groups. Seven patients in each group withdrew from the study ( $\vee$ Fig. 1). The baseline clinical characteristics were similar between the two groups ( $\triangleright$ Table 1 ). In total, 32 patients ( 16 males/16 females) aged $32.5 \pm 1$.6 years in the beinaglutide group and 32 patients ( 14 males/ 18 females) aged $32.3 \pm 1.4$ years in the metformin group completed the 12-week treatment. Similar proportions of obesity-related complications occurred in each group, including NAFLD, impaired glucose regulation, hyperuricaemia, and hypertension ( $\triangleright$ Table 1 ). 
- Table 1 Participant characteristics at baseline and after 12 weeks of treatment with beinaglutide or metformin.

\begin{tabular}{|c|c|c|c|c|c|c|c|}
\hline & \multicolumn{2}{|c|}{ Beinaglutide } & \multicolumn{2}{|c|}{ Metformin } & \multirow{2}{*}{$\begin{array}{l}P \\
\text { base- } \\
\text { line }\end{array}$} & \multirow{2}{*}{$\begin{array}{l}\text { Estimated } \\
\text { treatment } \\
\text { difference, } \\
\text { beinaglutide vs. } \\
\text { metformin (mean, } \\
95 \% \mathrm{Cl} \text { ) }\end{array}$} & \multirow{2}{*}{$\begin{array}{l}P \text { between } \\
\text { the two } \\
\text { groups }\end{array}$} \\
\hline & Baseline & 12 weeks & Baseline & 12 weeks & & & \\
\hline Number (n) & 32 & - & 32 & - & & & \\
\hline Age (y) & $32.5 \pm 1.6$ & - & $32.3 \pm 1.4$ & - & - & - & - \\
\hline Sex (male/female) & $16 / 16$ & - & $14 / 18$ & - & - & - & - \\
\hline Weight $(\mathrm{kg})$ & $94.0 \pm 2.5$ & $84.9 \pm 2.2^{* *}$ & $88.0 \pm 2.5$ & $83.4 \pm 2.4^{* *}$ & 0.090 & $-4.5(-6.9$ to -2.2$)$ & $<0.001$ \\
\hline BMI $\left(\mathrm{kg} / \mathrm{m}^{2}\right)$ & $32.3 \pm 0.4$ & $29.2 \pm 0.5^{* *}$ & $31.2 \pm 0.6$ & $29.6 \pm 0.6^{* *}$ & 0.142 & $-1.5(-2.2$ to -0.7$)$ & $<0.001$ \\
\hline$W C(\mathrm{~cm})$ & $105.9 \pm 1.5$ & $95.7 \pm 1.7^{* *}$ & $102.0 \pm 1.8$ & $96.4 \pm 1.8^{* *}$ & 0.085 & $-4.7(-8.0$ to -1.5$)$ & 0.005 \\
\hline SBP (mmHg) & $127.2 \pm 2.6$ & $124.0 \pm 1.9$ & $124.2 \pm 2.5$ & $122.3 \pm 1.7$ & 0.383 & $-1.3(-7.6$ to 4.9$)$ & 0.675 \\
\hline $\mathrm{DBP}(\mathrm{mmHg})$ & $82.1 \pm 2.0$ & $77.8 \pm 1.4$ & $80.5 \pm 1.8$ & $80.1 \pm 1.9$ & 0.483 & $-3.8(-9.6$ to 2.9$)$ & 0.196 \\
\hline Number (n) & 27 & - & 27 & - & - & - & - \\
\hline $\operatorname{ALT}(\mathrm{U} / \mathrm{L})$ & $52.8 \pm 6.5$ & $33.0 \pm 6.3^{*}$ & $41.8 \pm 6.3$ & $27.9 \pm 4.6^{*}$ & 0.253 & $\begin{array}{l}-5.9(-25.3 \text { to } \\
13.5)\end{array}$ & 0.545 \\
\hline AST (U/L) & $31.7 \pm 2.5$ & $22.6 \pm 2.2^{*}$ & $26.5 \pm 2.7$ & $20.5 \pm 1.5^{*}$ & 0.176 & $-3.1(-9.9$ to 3.8$)$ & 0.375 \\
\hline $\mathrm{UA}(\mu \mathrm{mol} / \mathrm{L})$ & $450.0 \pm 17.0$ & $405.6 \pm 16.7^{* *}$ & $413.3 \pm 23.8$ & $419.0 \pm 25.8$ & 0.277 & $\begin{array}{l}-50.1(-87.8 \text { to } \\
12.4)\end{array}$ & 0.010 \\
\hline TG $(\mathrm{mmol} / \mathrm{L})$ & $1.5 \pm 0.1$ & $1.3 \pm 0.1$ & $1.8 \pm 0.2$ & $1.7 \pm 0.2$ & 0.061 & $-0.1(-0.5$ to 0.3$)$ & 0.614 \\
\hline $\mathrm{TC}(\mathrm{mmol} / \mathrm{L})$ & $4.4 \pm 0.1$ & $4.3 \pm 0.1$ & $4.3 \pm 0.2$ & $4.6 \pm 0.2$ & 0.836 & $-0.3(-0.7$ to 0.1$)$ & 0.180 \\
\hline $\mathrm{HDL}-\mathrm{C}(\mathrm{mmol} / \mathrm{L})$ & $1.1 \pm 0.1$ & $1.1 \pm 0.1$ & $1.2 \pm 0.2$ & $1.1 \pm 0.1$ & 0.604 & $0.1(-0.3$ to 0.5$)$ & 0.501 \\
\hline LDL-C (mmol/L) & $2.8 \pm 0.1$ & $2.7 \pm 0.1$ & $2.6 \pm 0.2$ & $2.8 \pm 0.2$ & 0.729 & $-0.2(-0.5$ to 0.1$)$ & 0.193 \\
\hline $\mathrm{HbA1c}(\%)$ & $5.4 \pm 0.1$ & $5.5 \pm 0.1$ & $5.4 \pm 0.1$ & $5.3 \pm 0.1$ & 0.439 & $0.01(-0.2$ to 0.2$)$ & 0.922 \\
\hline FBG (mmol/L) & $5.2 \pm 0.1$ & $5.1 \pm 0.1$ & $5.0 \pm 0.1$ & $4.9 \pm 0.1$ & 0.058 & $-0.03(-0.3$ to 0.2$)$ & 0.831 \\
\hline $\begin{array}{l}30 \mathrm{~min} \text { glucose } \\
(\mathrm{mmol} / \mathrm{L})\end{array}$ & $8.1 \pm 0.3$ & $7.6 \pm 0.2$ & $8.5 \pm 0.2$ & $8.1 \pm 0.2$ & 0.505 & $-0.1(-0.9$ to 0.7$)$ & 0.803 \\
\hline $\begin{array}{l}120 \mathrm{~min} \text { glucose } \\
(\mathrm{mmol} / \mathrm{L})\end{array}$ & $6.9 \pm 0.3$ & $6.2 \pm 0.2$ & $6.9 \pm 0.4$ & $6.9 \pm 0.3$ & 0.783 & $-0.6(-1.4$ to 0.3$)$ & 0.212 \\
\hline $\begin{array}{l}\text { Fasting insulin }(\mu \mathrm{lU} / \\
\mathrm{mL})\end{array}$ & $26.5 \pm 5.2$ & $14.9 \pm 1.2^{*}$ & $20.7 \pm 1.8$ & $17.6 \pm 1.8$ & 0.522 & $-8.4(-18.6$ to 1.8$)$ & 0.104 \\
\hline $\begin{array}{l}30 \text { min insulin }(\mu \mathrm{IU} / \\
\mathrm{mL})\end{array}$ & $125.1 \pm 9.9$ & $99.6 \pm 10.5^{*}$ & $140.6 \pm 13.9$ & $140.2 \pm 18.6$ & 0.221 & $\begin{array}{l}-25.2(-63.0 \text { to } \\
12.6)\end{array}$ & 0.186 \\
\hline $\begin{array}{l}120 \text { min insulin }(\mu \mathrm{IU} / \\
\mathrm{mL})\end{array}$ & $111.7 \pm 14.0$ & $68.8 \pm 7.2^{*}$ & $125.5 \pm 14.4$ & $102.2 \pm 12.0$ & 0.471 & $\begin{array}{l}-19.6(-61.6 \text { to } \\
22.4)\end{array}$ & 0.354 \\
\hline HOMA-IR & $6.2 \pm 1.3$ & $3.4 \pm 0.3^{*}$ & $4.6 \pm 0.4$ & $3.8 \pm 0.4$ & 0.403 & $-2.0(-4.5$ to 0.4$)$ & 0.107 \\
\hline Hypertension (n/\%) & $5 / 32(15.6)$ & - & $3 / 32(9.4)$ & - & 0.708 & - & - \\
\hline $\begin{array}{l}\text { Hyperuricaemia } \\
(\mathrm{n} / \%)\end{array}$ & $20 / 30(66.7)$ & $15 / 30(50)$ & 10/27 (37) & $10 / 27(37)$ & 0.025 & - & 0.140 \\
\hline $\operatorname{NAFLD}(\mathrm{n} / \%)$ & $31 / 32$ (96.9) & $25 / 32(78.1)$ & $27 / 29(93.1)$ & $24 / 29(82.8)$ & 0.600 & - & 0.481 \\
\hline IFG (n/\%) & $2 / 27(7.4)$ & $0 / 27(0)$ & $2 / 27(3.7)$ & $0 / 27(0)$ & 1.000 & - & - \\
\hline IGT (n/\%) & $5 / 27(18.5)$ & $5 / 27(18.5)$ & $8 / 27(29.6)$ & $8 / 27(29.6)$ & 0.526 & - & - \\
\hline $\begin{array}{l}\text { Hyperlipidaemia } \\
(\mathrm{n} / \%)\end{array}$ & $3 / 30(10)$ & $2 / 30(6.7)$ & $6 / 27(22.2)$ & $4 / 27(14.8)$ & 0.283 & - & 1.000 \\
\hline $\begin{array}{l}\text { Abbreviations: SBP, sy } \\
\text { mass index; FBG, fasti } \\
\text { model assessment of } \\
\text { NAFLD, non-alcoholic } \\
\text { indicative of significan }\end{array}$ & $\begin{array}{l}\text { = blood pressu } \\
\text { ood glucose; } \\
\text { in resistance; } \\
\text { liver disease; } \\
\text { ferences betw }\end{array}$ & $\begin{array}{l}\text { BP, diastolic blo } \\
\text { C, high-density } \\
\text { impaired fasting } \\
\text { total cholesterol } \\
\text { groups. }{ }^{*} P<0 .\end{array}$ & $\begin{array}{l}\text { ressure; ALT, a } \\
\text { rotein cholest } \\
\text { ose; IGT, impa } \\
\text { triglyceride; } 4 \\
{ }^{*} P<0.01 \text {, co }\end{array}$ & $\begin{array}{l}\text { e aminotran } \\
\text { HbA1c, glyc } \\
\text { glucose toler } \\
\text { ric acid; WC, } \\
\text { red with base }\end{array}$ & $\begin{array}{l}\text {; AST, } \\
\text { aemo } \\
\text { DL-C } \\
\text { ircum } \\
\text { reach }\end{array}$ & $\begin{array}{l}\text { rtate aminotransferase } \\
\text { n A1c; HOMA-IR, hom } \\
\text { density lipoprotein ch } \\
\text { רce; . } P<0.05 \text { were con } \\
\text { tment. }\end{array}$ & $\begin{array}{l}\text { MI, body } \\
\text { tasis } \\
\text { sterol; } \\
\text { ered }\end{array}$ \\
\hline
\end{tabular}



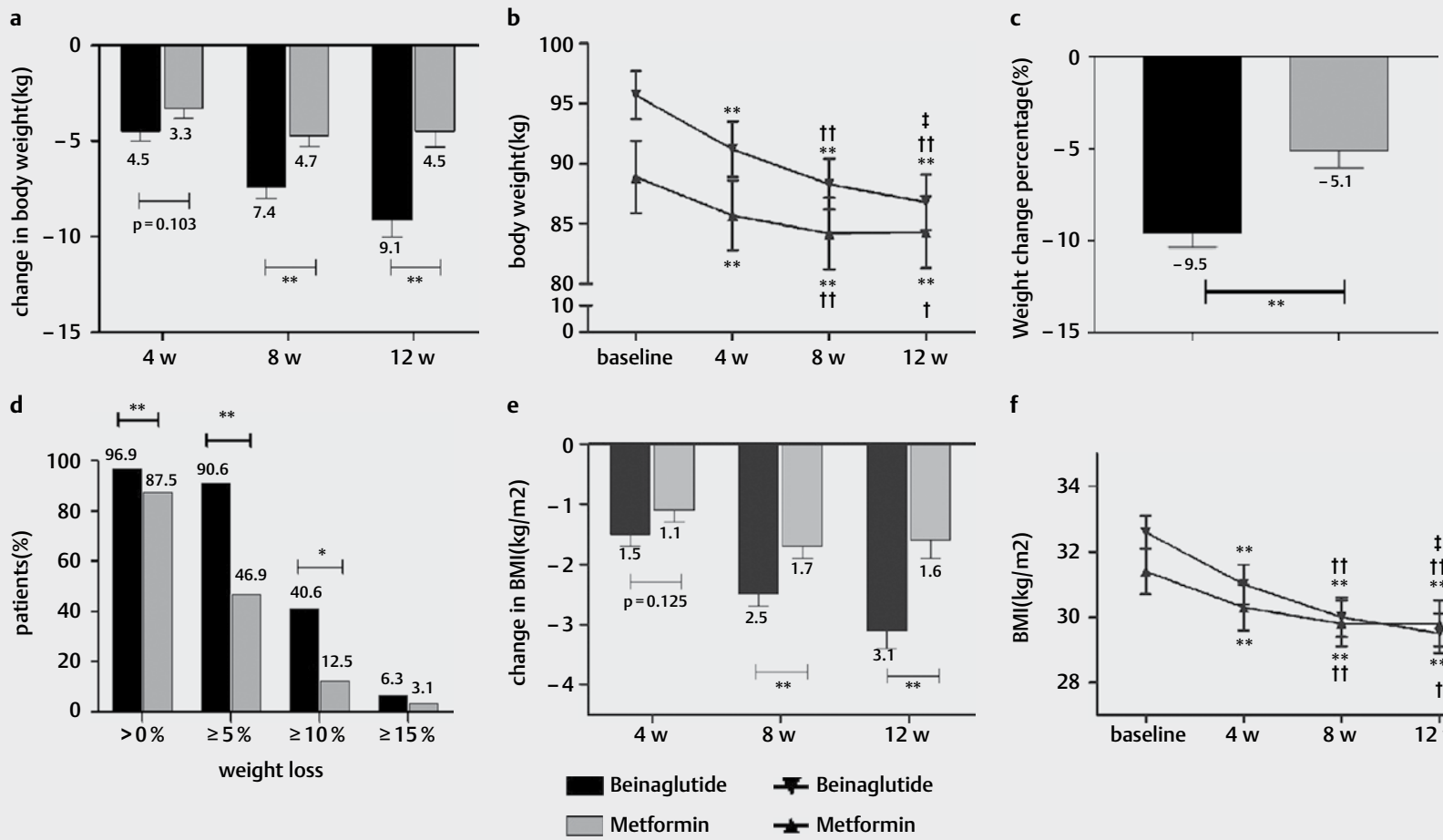

f

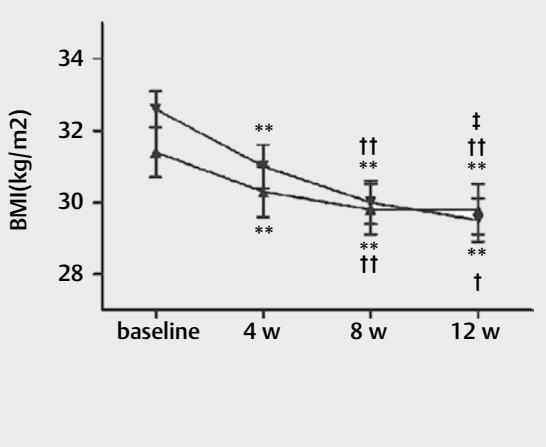

- Fig. 2 A comparison of changes in body weight (a), body weight (b), percentage weight loss (c), proportion of patients who lost at least $0,5,10$, and $15 \%$ of their initial body weight (d), changes in BMI (e), and BMI (f) during 12 weeks of treatment between beinaglutide or metformin groups $\left({ }^{*} P<0.05,{ }^{*}{ }^{*} P<0.01\right)$. a, c, d, and $\mathrm{e}^{* *} P<0.001 * P<0.05$; $\mathrm{b}$ and $\mathrm{f} * * P<0.001{ }^{*} P<0.05$ follow-up points vs. baseline. $\dagger \dagger P<0.001 \dagger P<0.05$ follow-up points vs. 4 weeks. $\ddagger P<0.05$ follow-up points vs. 8 weeks. BMI, body mass index. .

\section{Primary endpoint}

There was a downward trend in body weight during the 12 weeks follow-up period and more weight loss was observed at 8 weeks and 12 weeks in the beinaglutide group than in the metformin group ( $\triangleright$ Fig 2a, b). At the end of the study, participants in the beinaglutide group lost a mean of $9.5 \pm 0.8 \%(9.1 \pm 0.9 \mathrm{~kg})$ of their body weight, whereas those in the metformin group lost a mean of $5.1 \pm 0.9 \%(4.5 \pm 0.8 \mathrm{~kg})$ of their body weight ( $\vee$ Fig. 2 a, c). Patients in the beinaglutide group showed a greater decrease in body weight ( $\triangle=-4.5 \mathrm{~kg} ; 95 \%$ confidence interval $(\mathrm{Cl}),-6.9$ to $-2.2 \mathrm{~kg}$ ) than those in the metformin group at 12 weeks of treatment $(P<0.01)$ ( $\vee$ Table 1$)$. More patients lost $\geq 5$ or $\geq 10 \%$ of their body weight in the beinaglutide group than in the metformin group (90.6 vs. $40.6 \%$ and 46.9 vs. $12.5 \%$, respectively; $P<0.05$ ). However, the proportion of patients who lost $\geq 15 \%$ of their body weight did not significantly differ between the beinaglutide and metformin groups ( 6.3 and $3.1 \%$, respectively, $P=0.556$ ) ( $\triangleright$ Fig. 2 d). Overall, approximately $96.9 \%$ of participants in the beinaglutide group and around $87.5 \%$ of those in the metformin group lost weight ( $\triangleright$ Fig. $2 \mathrm{~d}$ ).

\section{$\mathrm{BMI}$ and waist circumference}

BMI and waist circumference of the participants decreased significantly in the beinaglutide and metformin groups during the 12 weeks of treatment (all $P<0.01$ vs. baseline) ( $\vee$ Fig. 2 e, $\mathbf{f} ; \triangleright$ Table 1). The beinaglutide group showed a greater decrease in BMI $\left(3.1 \pm 0.3 \mathrm{~kg} / \mathrm{m}^{2}\right.$ vs. $1.6 \pm 0.3 \mathrm{~kg} / \mathrm{m}^{2}, \Delta=-1.5 \mathrm{~kg} / \mathrm{m}^{2} ; 95 \% \mathrm{Cl},-2.2$ to $\left.-0.7 \mathrm{~kg} / \mathrm{m}^{2}\right)$ and waist circumference $(\Delta=-4.7 \mathrm{~cm} ; 95 \%$
$\mathrm{Cl},-8.0$ to $-1.5 \mathrm{~cm}$ ) than did the metformin group (both $P<0.01$ ) ( Table 1, $\triangleright$ Fig. 2e).

\section{Body composition, basal metabolic rate, and non- alcoholic fatty liver}

A total of 27 of 28 participants in the beinaglutide group and 29 of 30 in the metformin group had their body composition evaluated along with liver steatosis and stiffness measures at baseline and 12 weeks later. A significant decrease in body fat mass was observed, including total, trunk, limb, android, and gynoid fat and the percent body fat following both treatments $(P<0.01)$ ( $\triangleright$ Table 2$)$. A greater decrease in total fat mass ( $\triangle=-2.9 \mathrm{~kg} ; 95 \% \mathrm{Cl},-4.7$ to $-1.0 \mathrm{~kg} ; P<0.01)$, trunk fat mass ( $\triangle=-2.0 \mathrm{~kg} ; 95 \% \mathrm{Cl},-3.2$ to $-0.8 \mathrm{~kg} ; P<0.01)$, limb fat mass $(\triangle=-0.9 \mathrm{~kg} ; 95 \% \mathrm{Cl},-1.6$ to $-0.1 \mathrm{~kg} ; P<0.05)$, android fat mass $(\triangle=-0.5 \mathrm{~kg} ; 95 \% \mathrm{Cl},-0.7$ to $-0.2 \mathrm{~kg} ; P<0.01)$, gynoid fat mass ( $\triangle=-0.4 \mathrm{~kg} ; 95 \% \mathrm{Cl},-0.7$ to $-0.2 \mathrm{~kg} ; P<0.01$ ), and percent body fat mass $(\triangle=-1.7 \% ; 95 \% \mathrm{Cl},-3.1$ to $-0.4 \mathrm{~kg} ; P<0.05)$ in the beinaglutide group than in the metformin group ( $\vee$ Table 2 ). Beinaglutide significantly decreased the total, limb, android, and gynoid lean tissue masses $(P<0.05)$, and metformin significantly decreased the limb and gynoid lean tissue masses $(P<0.01)$; similar reductions in lean tissue mass were observed between the two groups ( $\vee$ Table 2 ).

Generally, the beinaglutide group experienced a greater loss of body fat mass, including total, trunk, limb, android, as well as gynoid mass, than of lean tissue mass in the same regions $(P<0.05)$ $(\triangleright$ Fig. 3). In the metformin group, the reductions in total, trunk, 
- Table 2 FibroTouch results and body composition at baseline and after 12 weeks of treatment with beinaglutide or metformin.

\begin{tabular}{|c|c|c|c|c|c|c|c|}
\hline & \multicolumn{2}{|c|}{ Beinaglutide } & \multicolumn{2}{|c|}{ Metformin } & \multirow{2}{*}{$\begin{array}{l}P \\
\text { base- } \\
\text { line }\end{array}$} & \multirow{2}{*}{$\begin{array}{l}\text { Estimated treatment } \\
\text { difference, } \\
\text { beinaglutide vs. } \\
\text { metformin (mean, } \\
95 \% \mathrm{Cl} \text { ) }\end{array}$} & \multirow{2}{*}{$\begin{array}{l}P \text { between } \\
\text { the two } \\
\text { groups }\end{array}$} \\
\hline & Baseline & 3 months & Baseline & 3 months & & & \\
\hline Number(n) & 28 & - & 29 & - & - & - & - \\
\hline Fibro Touch & - & - & - & - & - & - & - \\
\hline LSM (kPa) & $8.5 \pm 0.6$ & $6.7 \pm 0.4^{*}$ & $8.3 \pm 0.7$ & $6.7 \pm 0.3^{*}$ & 0.994 & $-0.2(-2.0$ to 1.5$)$ & 0.794 \\
\hline $\mathrm{CAP}(\mathrm{dB} / \mathrm{m})$ & $306.1 \pm 6.3$ & $270.2 \pm 5.5^{* *}$ & $295.3 \pm 6.5$ & $276.4 \pm 7.6^{*}$ & 0.247 & $-17.1(-35.1$ to 0.9$)$ & 0.062 \\
\hline Number (n) & 27 & - & 30 & - & - & - & - \\
\hline $\begin{array}{l}\text { Body } \\
\text { composition } \\
\text { (BIA) }\end{array}$ & - & - & - & - & - & - & - \\
\hline $\begin{array}{l}\text { Visceral fat } \\
\text { area }\left(\mathrm{cm}^{2}\right)\end{array}$ & $156.8 \pm 6.3$ & $127.2 \pm 6.6^{* *}$ & $158.6 \pm 7.8$ & $141.8 \pm 6.9^{*}$ & 0.542 & $-12.8(-25.4$ to -0.2$)$ & 0.046 \\
\hline $\begin{array}{l}\text { Basal } \\
\text { metabolic rate } \\
(\mathrm{kcal})\end{array}$ & $1634.4 \pm 45.5$ & $1601.3 \pm 44.0^{* *}$ & $1530.0 \pm 45.0$ & $1503.9 \pm 42.9^{*}$ & 0.124 & $-7.0(-31.3$ to 17.2$)$ & 0.564 \\
\hline $\begin{array}{l}\text { Body } \\
\text { composition } \\
\text { (DXA) }\end{array}$ & - & - & - & - & & - & \\
\hline $\begin{array}{l}\text { Percentage } \\
\text { body fat (\%) }\end{array}$ & $38.4 \pm 1.1$ & $34.7 \pm 1.2^{* *}$ & $39.2 \pm 0.8$ & $37.2 \pm 1.0^{* *}$ & 0.210 & $-1.7(-3.1$ to -0.4$)$ & 0.012 \\
\hline $\begin{array}{l}\text { Total Body fat } \\
\text { mass }(\mathrm{kg})\end{array}$ & $35.2 \pm 1.0$ & $29.1 \pm 1.1^{* *}$ & $33.8 \pm 1.1$ & $30.5 \pm 1.2 * *$ & 0.748 & $-2.9(-4.7$ to -1.0$)$ & 0.003 \\
\hline Trunk fat (kg) & $20.5 \pm 0.7$ & $16.6 \pm 0.8^{* *}$ & $19.0 \pm 0.8$ & $17.1 \pm 0.7^{* *}$ & 0.199 & $-2.0(-3.2$ to -0.8$)$ & 0.002 \\
\hline Limb fat $(\mathrm{kg})$ & $13.6 \pm 0.5$ & $11.4 \pm 0.4^{* *}$ & $13.7 \pm 0.6$ & $12.4 \pm 0.6^{* *}$ & 0.919 & $-0.9(-1.6$ to -0.1$)$ & 0.021 \\
\hline $\begin{array}{l}\text { Android fat } \\
(\mathrm{kg})\end{array}$ & $3.7 \pm 0.2$ & $2.8 \pm 0.2 * *$ & $3.2 \pm 0.2$ & $2.8 \pm 0.2 * *$ & 0.102 & $-0.5(-0.7$ to -0.2$)$ & 0.001 \\
\hline Gynoid fat (kg) & $5.1 \pm 0.2$ & $4.2 \pm 0.2 * *$ & $4.9 \pm 0.2$ & $4.5 \pm 0.2^{* *}$ & 0.566 & $-0.4(-0.7$ to -0.2$)$ & 0.002 \\
\hline $\begin{array}{l}\text { Total lean } \\
\text { tissue mass } \\
(\mathrm{kg})\end{array}$ & $54.1 \pm 2.0$ & $52.6 \pm 2.0 * *$ & $50.0 \pm 1.7$ & $49.6 \pm 1.6$ & 0.103 & $-1.1(-2.7$ to 0.5$)$ & 0.182 \\
\hline $\begin{array}{l}\text { Trunk lean } \\
\text { tissue }(\mathrm{kg})\end{array}$ & $24.5 \pm 0.8$ & $24.2 \pm 0.9$ & $22.7 \pm 0.7$ & $22.2 \pm 0.8$ & 0.082 & $0.2(-0.6$ to 0.9$)$ & 0.617 \\
\hline $\begin{array}{l}\text { Limb lean } \\
\text { tissue }(\mathrm{kg})\end{array}$ & $25.9 \pm 1.1$ & $24.7 \pm 1.0^{* *}$ & $23.7 \pm 0.9$ & $22.8 \pm 0.9^{* *}$ & 0.114 & $-0.3(-0.8$ to 0.1$)$ & 0.141 \\
\hline $\begin{array}{l}\text { Android lean } \\
\text { tissue }(\mathrm{kg})\end{array}$ & $3.8 \pm 0.2$ & $3.6 \pm 0.2^{*}$ & $3.5 \pm 0.1$ & $3.3 \pm 0.1$ & 0.067 & $-0.03(-0.2$ to 0.2$)$ & 0.770 \\
\hline $\begin{array}{l}\text { Gynoid lean } \\
\text { tissue (kg) }\end{array}$ & $8.9 \pm 0.4$ & $8.6 \pm 0.3^{* *}$ & $8.1 \pm 0.3$ & $7.8 \pm 0.3^{* *}$ & 0.070 & $-0.1(-0.3$ to 0.1$)$ & 0.228 \\
\hline
\end{tabular}

and android fat masses were greater than those of lean tissue masses in the same regions $(P<0.05)$ ( $>$ Fig. 3 ).

Visceral fat area and basal metabolic rate significantly decreased in the beinaglutide group (from $156.8 \pm 6.3 \mathrm{~cm}^{2}$ to $127.2 \pm 6.6 \mathrm{~cm}^{2}$, $P<0.01$; from $1634.4 \pm 45.5 \mathrm{kcal}$ to $1601.3 \pm 44.0 \mathrm{kcal}, P<0.01$, respectively) and in the metformin group (from $158.6 \pm 7.8 \mathrm{~cm}^{2}$ to $141.8 \pm 6.9 \mathrm{~cm}^{2}, P<0.05$; from $1530.0 \pm 45.0 \mathrm{kcal}$ to $1503.9 \pm 42.9 \mathrm{kcal}$, $P<0.05$, respectively) ( $\vee$ Table 2$)$. Changes in visceral fat area and basal metabolic rate were similar in both groups ( $\triangleright$ Table 2 ).

Similarly, LSM and CAP decreased significantly in the beinaglutide group (from $8.5 \pm 0.6 \mathrm{kPa}$ to $6.7 \pm 0.4 \mathrm{kPa}, P<0.05$; from
$306.1 \pm 6.3 \mathrm{~dB} / \mathrm{m}$ to $270.2 \pm 5.5 \mathrm{~dB} / \mathrm{m}, P<0.01$, respectively) and in the metformin group (from $8.3 \pm 0.7 \mathrm{kPa}$ to $6.7 \pm 0.3 \mathrm{kPa}, P<0.01$; from $295.3 \pm 6.5 \mathrm{~dB} / \mathrm{m}$ to $276.4 \pm 7.6 \mathrm{~dB} / \mathrm{m}, P<0.05$, respectively) ( $\triangleright$ Table 2). Similar changes in LSM and CAP were observed between the two groups ( $\triangleright$ Table 2 ). Beinaglutide and metformin treatments caused significant $(P<0.05)$ and similar reductions in serum ALT and AST levels ( $\triangleright$ Table $\mathbf{1})$.

\section{Glucose and lipid levels and insulin resistance}

There were no significant differences in serum glycated haemoglobin A1c and glucose levels at 0,30, and 120 min during the $75 \mathrm{~g}$ 


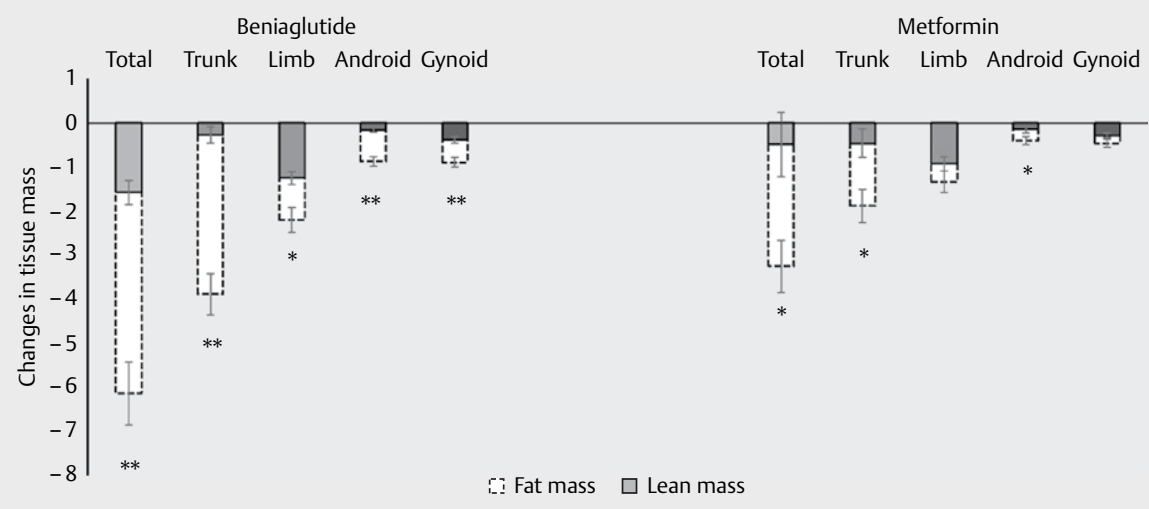

- Fig. 3 Changes in fat mass and lean tissue mass in the same region after treatment with beinaglutide or metformin $\left({ }^{*} P<0.05,{ }^{*} P<0.01\right)$.

- Table 3 On-treatment (beinaglutide or metformin) adverse events.

\begin{tabular}{|l|l|l|c|}
\hline & Beinaglutide & Metformin & \multirow{2}{*}{ P-value } \\
\cline { 2 - 3 } & $\mathbf{N}$ (\%) & $\mathbf{N ~ ( \% )}$ & \\
\hline Constipation & 0 & $1(2.6)$ & 1.000 \\
\hline Diarrhoea & 0 & $17(43.6)$ & $<0.001$ \\
\hline Nausea & $23(59.0)$ & $2(5.1)$ & $<0.001$ \\
\hline Vomiting & $8(20.5)$ & 0 & 0.005 \\
\hline Dizziness & $13(33.3)$ & $2(5.1)$ & 0.002 \\
\hline Headache & 0 & 0 & - \\
\hline Fatigue & $2(5.1)$ & $1(2.6)$ & 1.000 \\
\hline Gastroenteritis & 0 & 0 & - \\
\hline Nasopharyngitis & 0 & 0 & - \\
\hline Injection site Swelling & 0 & - & - \\
\hline Palpitation & $1(2.6)$ & 0 & 1.000 \\
\hline $\begin{array}{l}\text { Serious Adverse } \\
\text { events }\end{array}$ & 0 & 0 & - \\
\hline Hypoglycaemia & 0 & 0 & - \\
\hline
\end{tabular}

glucose tolerance test within or between the two groups, and the serum lipid profiles remained constant in both groups ( $\triangleright$ Table 1 ). Beinaglutide treatment resulted in a greater reduction in serum fasting, 30-min, and 120-min insulin levels and HOMA-IR levels (all $P<0.05$ ), whereas in the metformin group, serum fasting and 120 min insulin levels and HOMA-IR levels showed only a decreasing trend ( $\triangleright$ Table 1 ).

\section{Serum uric acid and blood pressure}

After 12 weeks of treatment, serum uric acid decreased significantly only in the beinaglutide group $(P<0.01)$, and beinaglutide caused greater reductions in the serum uric acid than metformin $(P<0.05)$. No noticeable change in blood pressure was observed in either group ( $\triangleright$ Table 1 ).

\section{Adverse events}

Gastrointestinal intolerance was the most common adverse event in the beinaglutide and metformin groups. In the beinaglutide group, $59.0 \%$ of patients had nausea, and $20.5 \%$ experienced vomiting, which was higher than that in the metformin group (5.1 and
$0 \%$, respectively) $(P<0.01)$, whereas $43.6 \%$ of patients had diarrhoea during metformin treatment, which was higher than that in patients during beinaglutide treatment $(P<0.01)$. Dizziness was also a common adverse event in the beinaglutide group, with $33.3 \%$ of patients experiencing transient dizziness during the trial, which was higher than that in the metformin group $(P<0.01)$. Most adverse events occurred in the first four weeks after enrolment, particularly in the first two weeks, and then gradually eased. Four patients in the beinaglutide group withdrew because of mild or moderate dizziness, and two patients in the metformin group withdrew because of diarrhoea. There were no serious adverse events and no hypoglycaemic events ( $\triangleright$ Table 3 ).

\section{Discussion and Conclusions}

Beinaglutide, at a thrice-daily dose of $0.2 \mathrm{mg}$, resulted in greater weight loss than metformin at a thrice-daily dose of $0.5 \mathrm{~g}$ in nondiabetic patients who were obese/overweight and who had been instructed to consume a limited-energy diet and engage in $150 \mathrm{~min}$ of physical activity weekly. Most patients (96.9\%) lost weight, and the mean change in body weight following beinaglutide treatment was $-9.5 \pm 0.8 \%(-9.1 \pm 0.9 \mathrm{~kg})$. The reduction in body weight, $\mathrm{BMI}$, and waist circumference, as well as the proportion of patients who lost not $<5$ or $10 \%$ of their body weight, was higher in the beinaglutide group.

Although the mean body weights at baseline in the beinaglutide group and the metformin group were 94.0 and $88.0 \mathrm{~kg}$, respectively, and the mean basal metabolic rate was about $100 \mathrm{kcal}$ lower in the metformin group, these differences in basal markers between the two groups were not significant. In addition, there was no significant difference in BMI at baseline between the two groups. Thus, this study examining the effect of these two medicines on inducing weight loss is valid.

Several other GLP-1RAs have been studied in a similar setting in the past. In 12 -week studies, liraglutide $(3.0 \mathrm{mg} / \mathrm{d})$ resulted in a mean weight loss of $6.3 \mathrm{~kg}$ and $57.1 \%$ of patients had a weight loss $\geq 5 \%$. Similarly, exenatide treatment ( $10 \mu \mathrm{g}$, twice daily) showed a mean weight loss of $4.29 \mathrm{~kg}$ with $47 \%$ of patients achieving a weight loss $\geq 5 \%[23,24]$. In a 52 -week study, subcutaneous injection of semaglutide $(0.4 \mathrm{mg} / \mathrm{d})$ resulted in a mean weight loss 
of $15.5 \mathrm{~kg}$ (13.8\%) with $91 \% / 74 \%$ of patients achieving $\geq 5 \% / \geq 10 \%$ weight loss, respectively [25]. Among the current GLP-1RAs, only liraglutide $(3.0 \mathrm{mg} / \mathrm{d})$ is approved for weight loss treatment in patients with obesity among all hypoglycaemic drugs [26]. Our data are the first to show that in patients who are overweight/obese and non-diabetic, the short-acting GLP-1RA beinaglutide $(0.6 \mathrm{mg} / \mathrm{d})$ is able to produce a weight loss of $9.1 \mathrm{~kg}(9.5 \%)$ with $90.6 \% / 46.9 \%$ of patients achieving a weight loss of $\geq 5 \% / \geq 10 \%$. This seems better than the weight loss achieved with liraglutide $(3.0 \mathrm{mg} / \mathrm{d})$ and exenatide (10 $\mu \mathrm{gID})$, but might be inferior to that achieved with semaglutide $(0.4 \mathrm{mg} / \mathrm{qd})$ [23-25]. However, the smaller number of patients, shorter observational time, and single ethnic background of the present study do not allow a fair comparison with the findings of these previous studies, and thus, a head-to-head multicentre and multi-ethnic study comparing these GLP-1RAs is necessary. In addition, the weight loss induced by beinaglutide in the present study is much the same as that observed in patients with T2DM who lost a mean of $10.5 \mathrm{~kg}$ (9.5\%) of their body weight after three months of treatment [15].

The benefits of treatment with GLP-1RAs include diminishing fat mass, particularly trunk and visceral fat in patients who are overweight/obese or have T2DM/prediabetes [27-29], which is likely to be related to delayed food absorption [30]. Other studies have shown the beneficial effects of metformin in reducing trunk and visceral fat mass in patients with T2DM $[18,27]$. Consistent with these findings, we found a significant decrease in total, limb, trunk, android, gynoid, and percent body fat following treatment with both beinaglutide and metformin, with beinaglutide showing stronger effects. Similar to a previous study examining weight loss at a liraglutide dose of $1.2 \mathrm{mg} / \mathrm{qd}$ or $1.8 \mathrm{mg} / \mathrm{qd}$ in patients with T2DM [27, 29], we also observed that the weight loss induced by beinaglutide was due to a reduction in body fat content rather than a reduction in lean tissue mass.

The LSM and CAP levels, as well as the serum ALT and AST levels, decreased significantly in both the beinaglutide and metformin groups, suggesting an improvement in NAFLD in response to both medicines. Previous studies have shown that 24 weeks of treatment with liraglutide or metformin monotherapy effectively reduced intrahepatic fat content and improved liver function in patients with T2DM and NAFLD [31]. Additionally, one year of treatment with liraglutide improved pathological changes in patients with non-alcoholic steatohepatitis [32]. Likewise, three years of treatment with exenatide also decreased serum ALT and AST levels in patients with T2DM [9]. A reduction in body weight and fat mass have been found to be closely related to a decrease in ALT and AST $[9,27]$. In the present study, the observed reduction in trunk fat content, particularly in the android region, in response to beinaglutide and metformin may help alleviate NAFLD.

GLP-1RAs have been shown to regulate postprandial glucagon release and insulin secretion in a glucose-dependent manner $[30,33]$. The patients in the present study showed no changes in glucose levels after 12 weeks of beinaglutide treatment. Importantly, no patient experienced hypoglycaemia, suggesting that the glucose-dependent mode of action of beinaglutide is safe in nondiabetic patients who are overweight/obese. This observation supports that reported by previous studies, in which there was no oc- currence of hypoglycaemia associated with metformin use in nondiabetic patients who are overweight/obese $[17,18]$.

The amount of adipose tissue is closely related to uric acid secretion, and that patients who are overweight/obese often exhibit hyperuricaemia, whereas fat loss, particularly visceral fat loss, significantly reduces uric acid secretion [34]. In the current study, the significantly reduced serum uric acid levels observed following beinaglutide treatment may be related to the greater weight loss and fat loss that occurred with the use of this drug. A low basal metabolic rate is a risk factor for increased body weight and fat mass [35]. In the present study, the basal metabolic rates of patients at baseline were lower than normal, and although the decrease in lean tissue mass was less than that of fat mass, a small degree of lean tissue loss was still observed following both treatments. A decreased basal metabolic rate is not conducive to maintaining weight loss. Although all participants were advised to maintain a limited-energy balanced diet and engage in physical activity, more targeted muscle-building exercises and dietary adjustments may help prevent loss of muscle mass [35, 36].

The safety profile of beinaglutide was similar to previous findings regarding other GLP-1RAs [7, 25]. Nausea and dizziness were the most common adverse events observed in our study. As previously observed for metformin [17], the main side effect in this study was diarrhoea. Overall, the total adverse reactions were similar between the two groups, and no serious adverse events occurred.

The limitations of our study include that it is a non-multicentre, non-double-blind, study with a short follow-up time, a relatively small sample size, and the lack of follow-up after discontinuation of the therapy. As a result, the time for which the weight loss was maintained and the rate of any subsequent weight gain were not assessed. This study is the first to examine the effect of beinaglutide on weight in non-diabetic subjects, with a prominent weight loss effect (nearly $10 \mathrm{~kg}$ ) after its use. However, a subsequent multicentre, double-blind, and extended follow-up study is needed, which can clarify whether beinaglutide is suitable for the long-term weight loss treatment in non-diabetics who are overweight/obese. The lack of a control treatment with orlistat, the usage of which is currently approved in China for weight loss, is another limitation of this study, as it would be helpful to clarify how beinaglutide compares to orlistat for weight reduction in patients who are overweight/obese.

In summary, treatment of non-diabetic patients who were overweight/obese with beinaglutide for 12 weeks achieved a greater degree of weight loss and fat mass reduction than with metformin treatment. The weight loss achieved with beinaglutide treatment mainly resulted from a reduction in fat mass rather than in lean tissue mass, thus ameliorating metabolic disorders. Beinaglutide may therefore be an option for Chinese patients who are overweight/ obese. This study strengthens the clinical data supporting the use of GLP-1RAs in non-diabetic patients who are overweight/obese.

\section{Author Contributions}

W.H.F. and Y.B. designed the study, supervised the research, and reviewed the manuscript. D.L.Z. reviewed the manuscript. L.J.G., H.H., and L.Z. collected data, performed the statistical analyses, 
and wrote the manuscript. N.J.Z. and Y.Z.F collected data. All authors read and approved the final manuscript.

\section{Acknowledgments}

The authors thank all participants, dietitian jing Wang (who provided diet guidance to each patient), and rehabilitation physician Ke Liu (who provided exercise guidance to each patient). We would also like to thank Editage [www.editage.cn] for English language editing.

\section{Funding}

This study was supported by grants from the National Natural Science Foundation of China $(81970704,81970689,81900787$. 81800752, and 81800719), National Key Research and Development Program of China (2016YFC1304804 and 2017YFC1309605), jiangsu Provincial Key Medical Discipline (ZDXKB2016012), Key Project of Nanjing Clinical Medical Science, Key Research and Development Program of Jiangsu Province of China (BE2015604 and BE2016606), Medical and Health Research Projects of Nanjing in jiangsu Province of China (YKK18067), Project of Standardised Diagnosis and Treatment of Key Diseases in Jiangsu Province of China (2015604), and Natural Science Foundation of Jiangsu Province of China (BK20201115). Drum Tower Hospital (affiliated with Nanjing University Medical School, China) provided sponsorship for article processing charges.

\section{Conflict of Interest}

All authors have no conflicts of interest, financial ties, or grant support to disclose.

\section{References}

[1] American Diabetes A Obesity management for the treatment of type 2 diabetes: standards of medical care in diabetes-2020. Diabetes Care 2020; 43: S89-597

[2] Mertens IL, Gaal LF. Overweight, obesity, and blood pressure: the effects of modest weight reduction. Obesity (Silver Spring, Md.) 2000; 8: $270-278$

[3] Warkentin LM, Das D, Majumdar SR et al. The effect of weight loss on health-related quality of life: systematic review and meta-analysis of randomized trials. Obesity Rev 2014; 15: 169-182

[4] Ma C, Avenell A, Bolland M et al. Effects of weight loss interventions for adults who are obese on mortality, cardiovascular disease, and cancer: systematic review and meta-analysis. Br Med J 2017; 359: j4849

[5] Bray GA, Fruhbeck G, Ryan DH et al. Management of obesity. Lancet 2016; 387: 1947-1956

[6] Dombrowski SU, Knittle K, Avenell A et al. Long term maintenance of weight loss with non-surgical interventions in obese adults: Systematic review and meta-analyses of randomised controlled trials. Br Med J 2014; 348: g2646

[7] Pi-Sunyer $\mathrm{X}$, Astrup A, Fujioka $\mathrm{K}$ et al. A randomized, controlled trial of $3.0 \mathrm{mg}$ of liraglutide in weight management. $\mathrm{N}$ Engl J Med 2015; 373 : $11-22$
[8] van Bloemendaal L, Ten Kulve JS, la Fleur SE et al. Effects of glucagonlike peptide 1 on appetite and body weight: focus on the CNS. J Endocrinol 2014; 221: T1-T16

[9] Klonoff DC, Buse JB, Nielsen LL et al. Exenatide effects on diabetes, obesity, cardiovascular risk factors and hepatic biomarkers in patients with type 2 diabetes treated for at least 3 years. Curr Med Res Opin 2008; 24: 275-286

[10] Vilsboll T, Christensen M, Junker AE et al. Effects of glucagon-like peptide- 1 receptor agonists on weight loss: systematic review and meta-analyses of randomised controlled trials. Br Med J 2012; 344: d7771-d7771

[11] Flint A, Raben A, Ersboll AK et al. The effect of physiological levels of glucagon-like peptide- 1 on appetite, gastric emptying, energy and substrate metabolism in obesity. Int J Obes Relat Metab Disord 2001; 25: 781-792

[12] Society CD. Chinese guideline for the prevention and treatment of type 2 diabetes mellitus (2020 edition). Chin J Endo Metab 2021; 37: 311-398

[13] Meier JJ. GLP-1 receptor agonists for individualized treatment of type 2 diabetes mellitus. Nat Rev Endocrinol 2012; 8: 728-742

[14] Application Manual for Benalutide Injection (Yishengtai). Approval Number: S20160007, Shanghai Renhui Bio-Pharmaceutical Co., Ltd.

[15] Zhang YL, Zhou C, Li XF et al. Beinaglutide showed significant weight-loss benefit and effective glycaemic control for the treatment of type 2 diabetes in a real-world setting: A 3-month, multicentre, observational, retrospective, open-label study. Obes Sci Pract 2019; 5: 366-375

[16] American Diabetes A Pharmacologic approaches to glycemic treatment: standards of medical care in diabetes-2018. Diabetes Care 2018; 41: S73-s85

[17] Desilets AR, Dhakal-Karki S, Dunican KC. Role of metformin for weight management in patients without type 2 diabetes. Ann Pharmacother 2008; 42: 817-826

[18] Zhou J, Massey S, Story D et al. Metformin: an old drug with new applications. Int J Mol Sci 2018; 19: 2863

[19] Seifarth C, Schehler B, Schneider HJ. Effectiveness of metformin on weight loss in non-diabetic individuals with obesity. Exp Clin Endocrinol Diabetes 2013; 121: 27-31

[20] Hui F, Zhang Y, Ren T et al. Role of metformin in overweight and obese people without diabetes: A systematic review and network metaanalysis. Eur J Clin Pharmacol 2019; 75: 437-450

[21] Guideline for primary care of obesity:practice version. 2019; Chin ] Gen Pract 2020: 102-103

[22] Domecq JP, Prutsky G, Leppin A et al. Drugs commonly associated with weight change: a systematic review and meta-analysis. J Clin Endocrinol Metab 2015; 100: 363-370

[23] Jensterle M, Kravos NA, Goričar K et al. Short-term effectiveness of low dose liraglutide in combination with metformin versus high dose liraglutide alone in treatment of obese PCOS: randomized trial. BMC Endocr Disord 2017; 17: 5

[24] Liu X, Zhang Y, Zheng S et al. Efficacy of exenatide on weight loss, metabolic parameters and pregnancy in overweight/obese polycystic ovary syndrome. Clin Endocrinol 2017; 87: 767-774

[25] O'Neil PM, Birkenfeld AL, McGowan B et al. Efficacy and safety of semaglutide compared with liraglutide and placebo for weight loss in patients with obesity: a randomised, double-blind, placebo and active controlled, dose-ranging, phase 2 trial. Lancet 2018; 392: 637-649

[26] Apovian CM, Aronne LJ, Bessesen DH et al. Pharmacological management of obesity: an Endocrine Society Clinical Practice Guideline. J Clin Endocrinol Metab 2015; 100: 342-362 
[27] Feng WH, Bi Y, Li P et al. Effects of liraglutide, metformin and gliclazide on body composition in patients with both type 2 diabetes and non-alcoholic fatty liver disease: a randomized trial. J Diabetes Investig 2019; 10: 399-407

[28] Larsen JR, Vedtofte L, Jakobsen MSL et al. Effect of liraglutide treatment on prediabetes and overweight or obesity in clozapine- or olanzapine-treated patients with schizophrenia spectrum disorder: A randomized clinical trial. JAMA Psychiatry 2017; 74: 719-728

[29] Jendle J, Nauck MA, Matthews DR et al. Weight loss with liraglutide, a once-daily human glucagon-like peptide- 1 analogue for type 2 diabetes treatment as monotherapy or added to metformin, is primarily as a result of a reduction in fat tissue. Diabetes Obes Metab 2009; 11: 1163-1172

[30] Drucker D]. Mechanisms of action and therapeutic application of glucagon-like peptide-1. Cell Metab 2018; 27: 740-756

[31] Feng W, Gao C, Bi Y et al. Randomized trial comparing the effects of gliclazide, liraglutide, and metformin on diabetes with non-alcoholic fatty liver disease. J Diabetes 2017; 9: 800-809
[32] Armstrong M], Gaunt P, Aithal GP et al. Liraglutide safety and efficacy in patients with non-alcoholic steatohepatitis (LEAN): a multicentre, double-blind, randomised, placebo-controlled phase 2 study. Lancet 2016; 387: 679-690

[33] Doyle ME, Egan JM. Mechanisms of action of GLP-1 in the pancreas. Pharmacol Ther 2007; 113: 546-593

[34] Tsushima Y, Nishizawa $H$, Tochino $Y$ et al. Uric acid secretion from adipose tissue and its increase in obesity. J Biol Chem 2013; 288: 27138-27149

[35] Piaggi P, Thearle MS, Bogardus $C$ et al. Lower energy expenditure predicts long-term increases in weight and fat mass. J Clin Endocrinol Metab 2013; 98: E703-E707

[36] Palmer BF, Clegg DJ. Strategies to counter weight loss-induced reductions in metabolic rate. Curr Sport Med Rep 2019; 18: 258-265 